\title{
Reproductive and Sexual Health Capability of Adolescent Girls: A Case study of Kashmir
}

\author{
Nurgiss Nazir \\ Nurgiss Nazir, Research Scholar (Sociology), Centre of Central Asian Studies, Kashmir University \\ DOI: 10.29322/IJSRP.11.01.2021.p10999 \\ http://dx.doi.org/10.29322/IJSRP.11.01.2021.p10999
}

\begin{abstract}
The study aims to explore the Reproductive and sexual health capabilities of Adolescent women in Kashmir valley. WHO defines adolescence as the segment of life between the ages of 10 to 19 years, this transitional stage of life is characterized by rapid physical and psychological development, sexual maturity and transition from dependence to relative independence. Adolescents are a group of apparently healthy individuals. The health status of an adolescent determines the health status in his/her adulthood. Many serious diseases in adulthood have their roots in adolescence. We can categorize the health needs of the adolescents broadly into three categories- physical, psychological and social. Reproductive health is an important area of concern in adolescence especially in girls and is a sensitive issue especially in Indian society. In such circumstances it is difficult to assess reproductive health problems and needs of the adolescents. Kashmir region has been going through turmoil and these years of turmoil has left its mark on the health of the inhabitants of Kashmir. Children including adolescents have different sociopsychological needs and necessities from rest of the peaceful states due to the conflict situation in the state. In this backdrop, our study will focus on the health and development needs of adolescent girls in Jammu and Kashmir with special focus on reproductive health capability.
\end{abstract}

Index Terms- capability, reproductive health, sexual health, adolescent woman, freedom.

\section{INTRODUCTION}

$\mathrm{W}$ orld Health Organisation (WHO) defines health as a State of complete physical, mental and social well-being of an individual and not just avoidance of disease. Women's health refers to the branch of medicine that focuses on the treatment and diagnosis of diseases and conditions that affect a woman's physical and emotional well-being. Health is an important factor that contributes to human wellbeing and economic growth. Generally, women's health receives attention only during pregnancy and the immediate post-partum period. A women's health agenda was first articulated at the Fourth World Conference on Women held in Beijing in 1995. In the resulting Beijing Declaration and Platform for Action, a roadmap for gender equality and women's empowerment was outlined, with a major focus on reproductive and sexual health (SRH) issues, which were the main killers of women then. As a result of this focus, major gains have been made in this area, with the maternal mortality in India coming down from $5.7 \%$ in 1990 to $2.8 \%$ in 2015 . $^{\mathrm{i}}$
Currently, women in India have to face numerous health issues, which ultimately affect the aggregate economy's output. Addressing the gender, class or ethnic disparities that exist in healthcare and improving the health outcomes can contribute to economic gain through the creation of quality human capital and increased levels of savings and investment. ${ }^{\text {ii }}$

In the overall Human Development Index, erstwhile state of Jammu and Kashmir ranked $10^{\text {th }}$ among the Indian states. It is noteworthy that among the three components of HDI, Jammu and Kashmir performs better than the national average on income index and education index but Health Index of Jammu and Kashmir is below the national average and far below than Kerala. Looking at the sex ratio in Indian states and UTs, Jammu and Kashmir has the second worst sex ratio i.e. only 889 females per 1000 males in 2011. The typical and adverse sex ratio of Jammu and Kashmir, lack of information about Maternal Mortality Ratio (MMR), poor educational attainments, the patriarchal cultural patterns, and the impact of political violence on the social order makes it very important to understand the state of health of women in general and the and the maternal health of women in particular. Jammu and Kashmir is an important part of India and presents unique climatic and cultural conditions. Its demographic pattern differs from that of the rest country with Muslims accounting for $56 \%$ of the population in 2007-08. The Total Fertility Rate (TFR) in 2008 was 2.2 which in rural areas is quite high (2.5) as compared to urban areas (1.5). Looking into the performance of indicators related to human development, Jammu and Kashmir has the lowest incidence of poverty compared to all other states in the country.iii These are some of the estimates regarding the health issues of women for-example 40 per cent of women (aged 15-49) are anaemic. 165 persons per 100,000 were estimated to have medically treated tuberculosis. The prevalence of the disease was slightly higher among women $(175$ per 100,000$)$ than among men (154 per 100,000), and it was also higher in rural areas (187 per $100,000)$ than in urban areas $(111$ per 100,000$){ }^{\text {iv }}$. It is also estimated that, of the 200 million pregnancies each year, approximately 50 percent are unplanned and 25 percent unwanted (Marjorie Agosin ed., 2009). According to some estimates, roughly 5 million abortions are performed annually in India, the large majority (about 4.5 million) illegally. ${ }^{\mathrm{v}}$ Unsafe abortion is a major cause of maternal mortality. In 2008, $49 \%$ of abortions were unsafe and contributed to $13 \%$ of maternal deaths. ${ }^{\mathrm{vi}}$ An estimated 222 million women in developing countries have an unmet need for contraceptives, either because the services are unavailable or cannot be accessed, or because of social barriers such as the need for parental or spousal consent ${ }^{\mathrm{vii}}$. Women should be able to make 
decisions about reproduction free of discrimination, coercion, and violence. Intimate-partner violence cuts across socioeconomic, religious and ethnic groups and across geographic areas, but women living in poverty, women with disabilities and adolescent girls are especially vulnerable. More than $30 \%$ of women and girls worldwide have experienced either physical and/or sexual intimate-partner violence or non-partner sexual violence ${ }^{\text {viii }}$.

Adolescent health is an increasingly important focus of public health efforts ${ }^{\mathrm{ix}}$. It is now quite widely accepted that adolescence is a time of transition involving multi-dimensional changes: biological, psychological (including cognitive) and social. Biologically, adolescents are experiencing pubertal changes, changes in brain structure and sexual interest, as a start. Psychologically, adolescents' cognitive capacities are maturing. Finally, adolescents are experiencing social changes through school and other transitions and roles they are assumed to play in family, community and school. These changes occur simultaneously and at different paces for each adolescent within each gender, with structural and environmental factors often affecting adolescents' development. Estimates of the number of adolescents worldwide vary due to the inconsistency with how international agencies and individual countries define the composition adolescence. The United Nations Population Fund (UNFPA) defines adolescents as being between the ages of 10 and 19. The World Programme of Action for Youth refers to adolescents as "youth" who are between the ages of 15 and 24. As such, the World Programme of Action for Youth's World Youth Report 2003 estimates that there are more than 1 billion youth aging 15 to 24 , with $85 \%$ inhabiting developing countries. Sixty percent of these young people live in Asia, 15\% in Africa, 10\% in Latin America and the Caribbean, and the remaining $15 \%$ in developed countries and regions. Countries and regions often define adolescence differently, according to cultural beliefs and practices. For instance, if adolescence is viewed as a transitional stage between childhood and adulthood, from dependence on family to autonomy, adolescence could terminate in one's late twenties or even early thirties in some regions. ${ }^{\mathrm{x}}$ Adolescence brings growth, change, opportunity, and, all too frequently, risks to reproductive health. The need for improved health and social services aimed at adolescents, including reproductive health services, is being increasingly recognized throughout the world. Spurred on by recommendations from the 1994 International Conference on Population and Development, organizations in many countries have created a range of programs to better meet the reproductive health needs of adolescents. While existing adolescent programs are too few and too limited to meet the global need, and have been inadequately evaluated, pilot projects and innovative efforts in many regions provide important lessons on what types of activities make a difference, and what do not. Many adolescents are sexually active (although not always by choice) and, in some regions, as many as half are married. Sexual activity puts adolescents at risk of various reproductive health challenges. Each year about 15 million adolescents aged 15-19 years give birth, as many as 4 million obtain an abortion, and up to 100 million become infected with a curable sexually transmitted disease (STD). Globally, 40 percent of all new human immunodeficiency virus (HIV) infections occur among 15-24 year olds; recent estimates are that 7,000 are infected each day. These health risks are influenced by many interrelated factors, such as expectations concerning early marriage and sexual relationships, access to education and employment, gender inequities, sexual violence, and the influence of mass media and popular culture. Adolescents often lack basic reproductive health information, skills in negotiating sexual relationships, and access to affordable, confidential reproductive health services. Concerns about privacy or the ability to pay, and real or perceived disapproval by service providers further limit access to services where they exist, as do legal barriers to information and services. Many adolescents lack strong stable relationships with parents or other adults whom they can talk to about their reproductive health concerns. $^{\mathrm{xi}}$

\section{THEORETICAL RELEVANCE}

Human beings have a dignity that deserves respect from laws and social institutions. This idea has many origins in many traditions; by now, it is at the core of modern democratic thought and practice all over the world. The idea of human dignity is usually taken to involve an idea of equal worth: rich and poor, rural and urban, female and male, all are equally deserving respect, just in virtue of being human, and this respect should not be abridged on account of a characteristic that is distributed by the whims of fortune. Often, too, this idea of equal worth is connected to ideas of freedom and opportunity: to respect the equal worth of persons is, among other things, to promote their ability to fashion a life in accordance with their own view of what is deepest and most important. But human dignity is frequently violated on grounds of sex. Many women all over the world find themselves treated unequally with respect to employment, bodily safety and integrity, basic nutrition and health care, education and political voice. In many cases these hardships are caused by their being women, and in many cases laws and institutions construct or perpetuate these inequalities. All over the world, women are resisting inequality and claiming the right to be treated with respect ${ }^{\mathrm{xii}}$.

\section{CAPABILITY APPROACH}

Some aspects of the capability approach can be traced back to, among others, Aristotle, Adam Smith, John Stuart Mill and Karl Marx, but the approach in its present form has been pioneered by the economist and philosopher Amartya Sen, and more recently also been significantly developed by the philosopher Martha Nussbaum. Sen argued that in social evaluations and policy design, the focus should be on what people are able to do and be, on the quality of their life, and on removing obstacles in their lives so that they have more freedom to live the kind of life which, upon reflection, they find valuable. ${ }^{\text {xiii }}$

Capability approach talks about freedom and the development of an environment suitable for flourishing. Capability refers to what people are actually able to be and do, rather than to what resources they have access to. It focuses on developing people's capability to choose a life that they have reason to value. The capability approach requires that human development is not taken as an abstract idea, but as lived capacities at the level of everyday life ${ }^{\text {xiv }}$.

The capability approach to well-being and development thus evaluates policies according to their impact on people's 
capabilities. It asks whether people are being healthy, and whether the resources necessary for this capability, such as clean water, access to medical doctors, protection from infections and diseases, and basic knowledge on health issues, are present. It asks whether people are well-nourished, and whether the conditions for this capability, such as sufficient food supplies and food entitlements, are met. It asks whether people have access to a high quality education, to real political participation, to community activities which support them to cope with struggles in daily life and which foster real friendships, to religions that console them and which can give them peace of mind. For some of these capabilities, the main input will be financial resources and economic production, but for others it can also be political practices, such as the effective guaranteeing and protection of freedom of thought, religion or political participation, or social or cultural practices, social structures, social institutions, public goods, social norms, traditions and habits. The capability approach thus covers the full terrain of human well-being. Development and well-being are regarded in a comprehensive and integrated manner, and much attention is paid to the links between material, mental, spiritual and social well-being, or to the economic, social, political and cultural dimensions of life ${ }^{\mathrm{xv}}$.

Unlike Sen, Nussbaum's capability framework identifies a well-detailed list of human capabilities that is supposed to be served by every human being in the world. Nussbaum typically uses the plural term "capabilities" in order to emphasize that the most important aspects or capabilities of people's quality of life are plural and are quantitatively distinct. She felt that health, bodily integrity, education, and other aspects of individual lives cannot be classified into a single term. Therefore, Nussbaum prefers to define her 'capability approach' as the "human development approach", because she is concerned with the capabilities of non-human animals as well as human beings. Due to that, Nussbaum is being praised for providing a richer, more applicable and realistic framework that can be used to evaluate every individual's well-being. Nussbaum's idea of well-being arises from the essence of reading Aristotle who argued about "good life" of every human. They further explained that like Aristotle, Nussbaum expands the approach to reinforce the environment where human beings can lead good life with their owned capabilities. Besides, it can be understood that Nussbaum's version of capability approach focuses not only on the household but each individual in the household. Here, each individual in the household is the unit of analysis of poverty.

Sen's core concepts are those of 'functionings' and 'capabilities'. A functioning is 'the various things a person may value doing or being' the practical realisation of one's chosen way of life. Capability refers to our freedom to promote or achieve valuable functionings. Capability is a combination (a capability set) of functionings someone can achieve, and from which he or she can choose one collection. The capability approach is based on the notion of life and living as a combination of various doings and beings, with quality of life to be assessed in terms of our capability to achieve valuable functionings. Functionings allow for different interpersonal conversion factors. It means if a person has Resources Capability and he/she is able to, but in real terms is he/she able to utilise his/her resources and capability. For example a person has bike and he knows how to ride, but is this person having a choice to ride around this bike or a person has money to buy food and is thus able to be nourished, but the question here is that does this person have a choice to buy such food which can nourish him. If we value being well nourished, or confident, or becoming a doctor, or a plumber, do we have the freedom to achieve these things, to live one kind of life, rather than another, to have 'real opportunity to accomplish what we value'? A capability is then 'the alternative combinations of functionings that are feasible' for a person to achieve. For Sen, his capability approach relates centrally to "freedom in the range of options a person has in deciding what life to lead'. Capability is thus the freedom to achieve various lifestyles that, having information about and having reflected upon, we value. The capability approach therefore argues for well-being and quality of life, not only income generation - a person's well-being is not simply a matter of how rich he or she is. The focus is not solely on income or consumption; instead, resources create opportunities, rather than being an end in themselves. Sen's conceptualisation of capabilities and functionings challenges a narrow income generation approach or, as it might currently be in the United Kingdom, a focus on education and employability as the key, even the only goal that matters for policy makers. While developing capabilities certainly includes an instrumental concern with the growth of national GDP, or individual income generation, this is seen as a means to expanding human capability 'to lead more worthwhile and more free lives. Educational quality and wellbeing in this approach would be assessed in terms of a person's ability to achieve valuable functionings. Such functionings (actual achievements) may range from the simple (being well nourished, having mobility) to the complex (being numerate and literate, taking part confidently in critical discussions with one's peers). Sen integrates securing and expanding intrapersonal and interpersonal freedoms (individual agency and social arrangements). Crucially, 'functionings' depend on both individual and institutional conditions and contexts within which potentials (freedom) can be achieved. Freedoms, as Sen points out, depend also on social and economic arrangements (e.g. education, health care), and on political and civil rights. Individual functionings will be inflected by a person's relative advantages in society, and enhanced by enabling public and policy environments, for example, a gender equity policy in schools. ${ }^{\text {xvi }}$ Notions of agency are central to the capability approach. At the boundary of functionings and capabilities is the matter of choice, where' a person exercises his or her agency, having the requisite set of capabilities, to make choices from a range of options and alternatives, if such a choice achieves his or her well-being. By agency, Sen means 'someone who acts and brings about change, and whose achievements are to be judged in terms of her own values and objectives, whether or not we assess them in terms of some external criteria as well'. Agency is one's ability to pursue goals that one values. Agency and well-being are then deeply connected. Importantly, choice in Sen's conceptualisation is not to be confused with neo-liberal advocates of individual choice. The crucial difference is that the capability approach is ethically individualistic; neo-liberalism by contrast is ontologically individualist. For the latter, the focus on individual autonomy individualises success and failure, and the social consequences that flow from personal choices. However, in Sen's formulation, individual freedom and agency strengthens social life, rather than fragmenting it. At issue is that Sen's work is informed by this 
ethical individualism - every diverse person counts; whereas the neo-liberal view grounded in ontological individualism is driven by selfish self-interest. Sen further works with the notion of 'the basic heterogeneity of human beings', thus human diversity is central to and explicit in his approach to equality, not an add-on factor. . $^{\text {vii }}$

\section{THE IDEA OF CHOICE AND FREEDOM}

The ideas of freedom and choice are central to the capability approach. There are two distinct ways in which choice appears in the capability approach: the act of choice and the scope of choice. We may describe these two aspects as the agency aspect and the opportunity aspect of choice respectively. To see the distinction and their respective importance, consider how one goes from capability to achieved functioning. Capability reflects the full range of possible levels of functioning that an individual can enjoy considering all the constraints and opportunities of acquiring commodities and then converting them into functionings.

Capability approach is concerned primarily with positive freedom. When the neoliberals champion the cause of market freedom they are essentially asking for absence of restraints on what market participants can choose to do (so long as some basic tenets of legal behaviour are observed, such as compliance with contracts, etc.). In so doing, they are trying to protect people's negative freedom. By contrast, the very concept of capability embodies a quintessentially positive conception of freedom. For instance, when we ask 'does a person have the capability to be well-nourished', what we mean is that, taking into account all the opportunities and constraints she faces in converting her endowments into the functionings she values, is she able to choose a functioning vector that gives her enough food to be wellnourished? If the answer is yes, then she does have that capability; in that case, she can also be said to enjoy the positive freedom to choose to be well-nourished. Being alive to this distinction between two types of freedom immediately makes it clear that just because the capability approach uses the language of freedom, it does not necessarily have to endorse the neoliberal conception of freedom $^{\text {xviii }}$. For Sen's capability approach is to what extent owned commodities allow a person to have a freedom of functioning in the society for their own well-being as they do not directly assure a state of being. Sen's approach focuses on real freedom that is on what people are able to do and not on what people should do to alleviate their impoverished situation.

Sexual and reproductive health is not limited to the absence of disease or dysfunction, nor is its importance confined to just the reproductive years. It includes the ability to understand and weigh the risks, responsibilities, outcomes and impacts of sexual actions and to practice abstinence when appropriate. It includes freedom from sexual abuse and discrimination and the ability of individuals to integrate their sexuality into their lives, derive pleasure from it, and to reproduce if they so choose. ${ }^{\mathrm{xix}}$ Choice factor is at the core to achieve the highest capability, relating choice factor to the adolescent reproductive health is a crucial phenomenon. The decision to choose for the better health is governed by various factors- based on various dimensions; an adolescent is dependent on (e.g.) parenting, economy, socialisation, geography etc. Adolescent is more vulnerable to the wrong choice formation and

This publication is licensed under Creative Commons Attribution CC BY

http://dx.doi.org/10.29322/IJSRP.11.01.2021.p10999 needs to be guided properly and according to the psychological needs.

\section{AdOLESCENT WOMEN'S HEALTH NEEDS}

Adolescent health is an increasingly important focus of public health efforts. In contrast to other age groups, mortality and morbidity rates for adolescents and young adults in Western countries have increased over the past few decades. Health status for adolescents now appears to be poorer than it was for their parents. Increased focus has been associated with broadened definitions of adolescent health. Public health now considers healthy behaviours in addition to health status (i.e., mortality and morbidity), and there is increasing consideration of adolescent development and coping within these formulations. ${ }^{\mathrm{xx}}$ Since the late 1980's there has been an increasing awareness of the need to pay special focus on the adolescent and their sexual and Reproductive Health (RH). ${ }^{\mathrm{xxi}}$ The sexual and RH behaviour of this age group will critically affect the global population growth pattern. ${ }^{\text {xii }}$

The mortality rate among adolescents is low as compared to other periods of the life span. In 1996, the major causes of adolescent mortality in the United States, using U.S. health statistics categories, were injury (including accidents, homicide, and suicide), cancer, heart disease, and acquired immunodeficiency syndrome. Major sources of morbidity are infectious disease, particularly sexually transmitted diseases, and substance abuse. This same pattern is seen in developing countries as paediatric care improves, marriage is postponed, and a pattern of urban migration for employment is established in young people. Although morbidity and mortality are relatively low, some types of disease show a peak incidence in the adolescent years. The highest incidence of hepatitis and infections of the gastrointestinal tract have been noted in the adolescent age range. The highest rate of near-fatal asthma attacks occurs in adolescence. Mid adolescence is the peak time for the onset of eating disorders. Pathologic sleep conditions such as sleep apnea and delayed sleep phase syndrome have their symptomatic onset in adolescence. In addition, adolescence is a time of symptomatic emergence for disease.

Several authors have proposed that early and late puberty are risk factors for later adult disorders, particularly brain dysfunction. Over the years, differences in cognitive ability and susceptibility to psychopathology have been attributed to early and late maturers. Influential hypotheses have been advanced concerning the role of delayed or faulty adolescent brain maturation in the aetiology of schizophrenia, and some direct evidence has been presented. These hypotheses are prompted by evidence that neural substrates implicated in schizophrenia mature during adolescence. Other outcomes for which age at puberty may be a risk factor include short stature, obesity, breast cancer, and polycystic ovary syndrome. Finally, the regression of clinical problems at adolescence bears consideration. ${ }^{\text {xiii }}$

Attention to adolescents by those in the reproductive health field originated with concerns about the risk behaviours and vulnerability of adolescents, especially in relation to early and unwanted pregnancy, unsafe abortion, sexually transmitted infections and HIV/AIDS. ${ }^{\text {xiv }}$ The effects of globalization, rising age at marriage, rapid urbanization and greater opportunities for 
socialization have heightened the risk of STIs, HIV/AIDS and unwanted pregnancy. While adolescents have unmet needs for reproductive health information and services, these are not addressed by parents, schools or the existing health care systems. Sex education should be a lifelong learning process based on the acquisition of knowledge and skills and development of positive values and attitude. Sex education aims to reduce the risks of potentially negative outcome from sexual behaviour such as fear and stigma of menstruation, unwanted and unplanned pregnancies and infection with STIs including HIV. Effective sex awareness program should start early before young people reach puberty more so before they have developed established patterns of behaviour.

The consequences of sexually transmitted infection (STI) and unplanned pregnancy can be devastating. Young women are at the start of their reproductive life and risk compromising their future fertility through tubal occlusion or ectopic pregnancy. In many areas, young women who get pregnant are withdrawn from school, further disadvantaging them. In countries where access to abortion is limited, the gynaecological consequences of "back street" abortion can be dire. While young men suffer fewer direct health consequences of early sex, infection or pregnancy can still have adverse consequences for them-for example, with respect to further education and training opportunities. Today's adolescents will determine the social fabric, economic productivity, and reproductive health and well-being of nations throughout the world in the coming decades. Worldwide, a variety of programs have tried to address the sexual and reproductive health needs of adolescents. Communications and other interventions designed to improve the sexual and reproductive health of adolescents needs to respond appropriately to the changing global context. ${ }^{\mathrm{xxv}}$

Consequently, a shift to a more holistic approach is taking place and a range of 'antecedents' of reproductive behaviour has been examined, e.g. the importance of schooling, age at marriage, connectivity to parents, partner involvement and health system characteristics. However, the goal remains the prevention of negative outcomes. An alternative is to think about reproductive outcomes in terms of healthy reproductive practices - accurate knowledge and information, availability and accessibility of youth-friendly services, ability to make responsible and informed decisions, couple communication and negotiation about sex, contraception and child bearing, later age at marriage and delayed on set of childbearing. Re-framing the terminology of these variables directs attention to a different range of determinants, many of which are even more fundamental than 'antecedents'. For adolescents, in developing countries especially, social and institutional restrictions may shape a large part of their actions. As societies change, however, personal ideals and aspirations often challenge existing norms and institutions and young people are often the agents of change. In fact, widespread ideals and aspirations among young people may be the main route to shifting from negative behaviours to more positive reproductive health outcomes. $^{\text {xxvi }}$ Many reproductive health programmes view adolescent girls solely as reproductive beings who are 'at risk'. The focus on risk behaviours provides an incomplete lens on adolescent girls' lives and has meant limited success for reproductive health programmes in the past. It is being argued that understanding and addressing the larger context of young women's lives and the aspirations may be critical in realising positive reproductive health outcomes. Adolescents in Kashmir often face severe poverty, limited access to education and health services and restrictive cultural and sexual norms.

\section{HEALTH NEEDS: EMPIRICAL EVIDENCES}

Kashmiri society is highly patriarchal, in which young adolescent women are less provided with the opportunities to practise their capability of health. Various hindrances in achievement of health capability make the life more difficult for the women in Kashmir. Structural arrangements are such that, the privileged section is more benefited.

Sumairah (name changed), age 19, under-graduate, is suffering from multiple disk problem into her back, the doctor has prescribed rest for a particular time period. While interview Sumairah revealed that she is not able take rest as she is survived with parents, two siblings, she has to take care of their everyday necessities. Sumairah said "I cannot afford to take rest at the cost of my family's suffering; my siblings are very young they need me, and my parents do a lot of hard work I have to serve them, my health is least important in comparison to the needs of my family". Because of this response to her illness, her health is deteriorating day by day and there is no improvement.

Razia (name changed) 20, unmarried, is suffering from various ailments, including PCOD (Polycystic ovary syndrome) and obesity, she is pursuing her $\mathrm{PhD}$. Currently. Her parents are intended to marry her but she is reluctant towards the decision because of her ailment. "The other home I will go after marriage will not understand my situation and that will be catastrophic for my health, though I want to get married but my health situation is not allowing me for the same, as I have been devastated by old relationship because of health problems only". She is on medication but her heath is not improving because of the constant stress regarding marriage and health. Society looks at ailment as incompetence of an individual and that substantiates the suffering of a patient.

Masooda (name changed) 16, is suffering from ovarian cyst from past two years. She is not seeking medical assistance for the problem, as her father is a diabetic patient and is on medication for which the family is spending a lot of money. "We are not economically so much well-off that we can afford the expenses of medication for two persons at a time, so we have decided to provide medical assistance to my father first, when he will recover then only will I think about myself'. Women do not prioritise their health, when it comes to make investment women's health is considered least important.

Beenish Bahshir (name changed) 15, "I realised some black stain on my private part when I was 13, and I shared about it with my father, as I don't have mother. He suggested me to use saline water, as it may be some kind of infection. Saline water provided some kind of relief, and it was finally my grandmother who took me to the gynaecologist, and I am being cured. I was highly disturbed mentally as it was constantly in my mind that I am suffering from something, which I can't share to anybody. It took three years to cure that, and these three years were of mental disturbance".

Every kind of ailment has an impact on the psychology of a patient, adolescent reproductive health particularly for girls under the constraint circumstances have a serious impact on mental 
health. Because of the fear of sharing and the proper response from the doctors, reproductive health ailment leads to psychological disturbance as well.

Samina sultan (name changed)17, "I have white discharge problem since 13, and I am not able to share this problem and seek medical help. I think it is normal and is a part of adolescence, the problem is growing with every passing day and I am not able to do anything about it".

Adolescents generally lack awareness regarding the reproductive health issues; it is very difficult for them to decide the normal and abnormal kind of health status, as they are in a constant changing phase. Bodily changes are triggered with other internal and psychological changes that lead to the ignorance as the culture of talking about the reproductive health is not prevalent in the society.

Towkina Rasheed (name changed) 18, "I had my period very early at the age of twelve, my first periods prolonged for 20-25 days. That time I was not able to make a decision what to do about $i$, when the situation turned worse after 25 days my mother took me to the gynaecologist, and she suggested, I am anaemic and needed to be taken care and well fed".

Adolescence is a phase of change, and proper care needs to be done. The body in this phase is in high demand of nutrients. Any negligence can cause a severe blow to the individual health. Adolescent girls lack that proper nutritional intake, that adversely affect their reproductive health in particular and health in general. Menstrual health plays an important role in women's sexual and reproductive life menstrual problems can be the warning signal of some underlying disease. Changes in menstrual pattern may affect her physical, psychological, social wellbeing besides creating great anxiety. It is an important component of overall health yet is ignored and given least priority. ${ }^{\text {xvii }}$ Learning about menstrual hygiene is a vital aspect of health education for adolescent girls. The onset of menstruation profoundly changes young women's lives. ${ }^{\text {xxviii }}$ Good hygiene, such as use of sanitary pads and adequate washing of the genital area, is important during menstruation. Women and girls of reproductive age need access to clean, soft, absorbent sanitary products. ${ }^{\text {xxix }}$ Learning about hygiene during menstruation is a vital aspect of health education for adolescent girls, as patterns that are developed in adolescence are likely to persist into adult life. ${ }^{\mathrm{xx}}$ Strips of towelling or cloth are not absorbent, lack cleanliness and may produce an odour. ${ }^{\text {xxi }}$

Sabena (name changed) 16, "when I got my first periods last year, I was so ashamed of sharing that with my mother that $i$ used some unclean cloth to ease myself and got infected severely, the irritation and itching was so severe that $i$ consulted my mother and she took me to the gynaecologist and $i$ was on medication for a month for that reason".

The adolescent girls are not given such environment that they can be open towards their parents regarding their problems and in this restrictive environment; they are more vulnerable to problems and reproductive health problems as well.

\section{CONCLUSION}

Women in society should be given such a place so that she could be free from any mental harassment caused by societal set up and could enjoy sound physical health. This is because apart from environmental factors, social factors are also responsible for affecting health of women. She could enjoy her place in society and so her position must be improved by removing evils pertaining to her and thus providing mental and hence physical health. In this backdrop the capability approach makes each person a bearer of value, and end in itself. Capability is thus a demanding notion, in its focus on the environment of choice, it is highly attentive to the goal of functioning, and instructs governments to keep it always in view. On the other hand, it does not push people into functioning: once the stage is fully set, the choice is theirs.

More extensive information on adolescent reproductive behaviour is limited, and surveys on youth attitudes about sexuality, sexual relations, and family planning are rare. For adolescents, in developing countries especially, social and institutional restrictions may shape a large part of their actions. However it is known that adolescents are not a homogenous group, their lives vary enormously by age, sex, marital status, class, region and cultural context, similarly their lives, sexual and $\mathrm{RH}$ needs may vary considerably across these different groups, cultures and regions. One of such regions is the Jammu and Kashmir. There is reason to believe that due to the geographic, economic and socio-cultural peculiarity, the adolescent are more susceptible to negative RH outcomes. In Kashmir particularly adolescent reproductive and sexual health issues have not been studied much, respondents are not open to provide the required response. Adolescent girls lack the proper awareness regarding the issue because of the rigid environment, which considers the discussion on $\mathrm{RH}$ as taboo and because of this silent environment they suffer more. Parents play a bigger part in maintaining the health of an adolescent, but as far as the study is concerned it is being observed that the adolescent girls are not comfortable to share their RH problems with parents, which make them more vulnerable to the RH issues.

Acknowledgement: The authors received no financial support for the research, authorship, and/or publication of this article.

\section{AUTHORS}

First Author - Nurgiss Nazir, Research Scholar (Sociology), Centre of Central Asian Studies, Kashmir University, Email: nargisnazir333@gmail.com, Phone: 6005023174. 
${ }^{\text {i }}$ Framing Women's Health Issues in 21 st Century India - A Policy Report The George Institute for Global Health India, May 2016. The George Institute for Global Health, India.

ii Women's Health, National Health Portal, https:/www.nhp.gov.in/healthlyliving/women-s-health

${ }^{\text {iii }}$ Muzaffar, N. (2015). Maternal Health and Social Determinants: A Study in Jammu and Kashmir, Public Health Research, 5(5), 144-145.

iv National Family Health Survey (NFHS-4) 2015-16: Jammu and Kashmir, available at https://ruralindiaonline.org/resources/national-family-health-survey-nfhs-4-2015-16-jammu-and-kashmir/

${ }^{\vee}$ UNICEF Children and Women in India: A Situation Analysis, New Delhi, 1990.

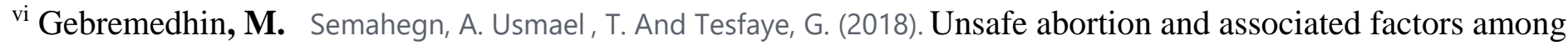
reproductive aged women in Sub-Saharan Africa: a protocol for a systematic review and meta-analysis, Syst Rev. Aug 25;7(1):130. doi: 10.1186/s13643-018-0775-9.

vii Family Planning Summit, New UNFPA/Guttmacher Study, The Partnership for Maternal, Newborn \& Child Health, 11 July

2012. Available at https://www.who.int/pmnch/media/news/2012/20120627_family_planning_summit/en/index8.html

viii Violence against women, World Health Organisation, available at https://www.who.int/news-room/factsheets/detail/violence-against-women

${ }^{\text {ix }}$ Millstein, S. G., Petersen, A. C., \& Nightingale, E. O. (Eds.). (1994). Promoting the health of adolescents: New directions for the twenty-first century. Oxford University Press on Demand.

${ }^{\mathrm{x}}$ UNICEF. (2005). Adolescent Development: Perspectives and Frameworks-A discussion Paper. United Nations Children's Fund New York. UNICEF, 3.

${ }^{x i}$ Outlook, Program for Appropriate Technology in Health (PATH), Volume 16, Number 3,

xii Nussbaum, M. (1999). Women and equality: The capabilities approach, International Labour Organization, Vol. 138, No. 3. 227.

xiii Robeyns, I. (2003). The Capability Approach: An Interdisciplinary Introduction, Amsterdam School of Social Sciences Research, 5-8.

xiv Walker,M. (2005). Amartya Sen's Capability Approach and Education, Educational Action Research, Volume 13, Number 1, 103-104

${ }^{\mathrm{xv}}$ Robeyns, I. (2003). The Capability Approach: An Interdisciplinary Introduction, Amsterdam School of Social Sciences Research,7-8

${ }^{\mathrm{xv}}$ Walker,M. (2005). Amartya Sen's Capability Approach and Education, Educational Action Research, Volume 13, Number 1, 104-105

${ }^{x v i i}$ Walker,M. (2005). Amartya Sen's Capability Approach and Education, Educational Action Research, Volume 13, Number 1, 104-106

xviii Osmani, S. R.( 2016). The Capability Approach and Human Development: Some Reflections, UNDP Human Development Report.9-16.

xix Satcher, D. (2001). The Surgeon General's call to action to promote sexual health and responsible sexual behavior. Washington, DC: US Department of Health and Human Services, 1.

${ }^{x x}$ Raphael, D., Brown, I., Rukholm, E., \& Hill-Bailey, P. (1996). Adolescent health: moving from prevention to promotion through a quality of life approach. Canadian Journal of Public Health/Revue Canadienne de Sante'e Publique, 87(2), 81.

${ }^{x x i}$ Population Reference Bureau (PRB). The world's Youth 2000. Washington.

${ }^{x x i i}$ Rani, M., \& Lule, E. (2004). Exploring the socioeconomic dimension of adolescent reproductive health: a multicountry analysis. International Family Planning Perspectives, 110.

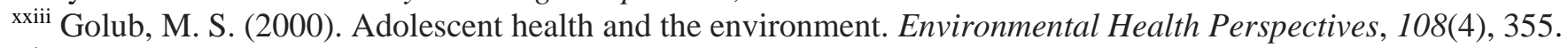

${ }^{\text {xxiv }}$ Hughes, J., \& McCauley, A. P. (1998). Improving the fit: adolescents' needs and future programs for sexual and reproductive health in developing countries. Studies in family planning, 233-245.

${ }^{x x v}$ Kotwal, N., Khan, N., \& Kaul, S. (2014). A review of the effectiveness of the interventions on adolescent reproductive health in developing countries. IJSRP, $4,1$. 
xxvi Mathur, S., Malhotra, A., \& Mehta, M. (2001). Adolescent girls' life aspirations and reproductive health in Nepal. Reproductive Health Matters, 9(17), Pp. 91-92.

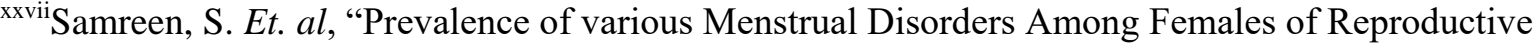

Age group of Kashmir: A Cross-Sectionsal Study. International journal of advanced research, 4(8), P. 349.

xxviii Snowden R, Christian B. (1983). Patterns and perceptions of menstruation. A World Health Organization International Collaboration Study. New York: St Martin's Press,.

xxix Harvey, P., Baghri, S., \& Reed, B. (2002). Emergency sanitation: assessment and programme design. WEDC, Loughborough University. p.60.

${ }^{x x x}$. Narayan, K., Srinivasa, D. K., Pelto, P. J., \& Veerammal, S. (2001). Puberty rituals reproductive knowledge and health of adolescent schoolgirls in south India. Asia-Pacific Population Journal, 16(2), 225-38.

xxxi . Federal Democratic Republic of Ethiopia, Ministry of Health. Personal hygiene extension package. Addis Ababa. February 2004. p. 17. 